\title{
Application of a Group Decision Support System in the Reform of Study Programmes
}

\author{
Andrej Škraba ${ }^{1}$, Alenka Baggia ${ }^{2}$ \\ University of Maribor, Faculty of Organizational Sciences \\ SI-4000 Kranj, Slovenia \\ 1andrej.skraba@,fov.uni-mb.si, ${ }^{2}$ alenka.baggia@ffov.uni- \\ $\underline{\mathrm{mb} . \mathrm{si}}$
}

\author{
Blaž Rodič \\ Faculty of information studies \\ SI-8000 Novo Mesto, Slovenia \\ blaz.rodic@fis.unm.si
}

Received: April 15, 2019. Revised: June 12, 2021. Accepted: October 16, 2021. Published: November 24, 2021.

\begin{abstract}
This paper presents the process and impact of the application of a group decision support system (GDSS) in the reform of post-Bologna graduate and postgraduate study programmes in two higher education institutions in Slovenia. Four experiments with four groups including both students and staff were performed. We have used the GDSS tool TeamWorks to organize, moderate and document meetings intended to develop possible answers to the question "How can we improve the content and execution of the study programmes?" The obtained results are to be used in the design of new study courses. Analysis of the idea gathering process dynamics represents important information for researchers in the field of group decision-making process dynamics. In addition to the experimental work the structure of a group decision support process is described and guidelines for the further development of tools and methodologies are presented.
\end{abstract}

Keywords-Group Decision Support System; Education; Decision Process Dynamics; Expert System; Study programme

\section{INTRODUCTION}

Due to increased competition in higher education environments, universities adopted modern information and communication technologies (ICT) with the aim of completing high quality educational processes [1]. Group Decision Support Systems (GDSS) provide a useful tool for group collaboration and effective decision-making process. Sessions supported by GDSS can be more goal oriented, meeting agenda is easier to enforce and the members of the group provide the direction to each other [2]. GDSS support affects group interaction processes by increasing information influence (accepting information from other members as a reality) and decreasing normative influence (desiring to conform to the expectations of other group members) [3],[4].

The reform of study programs is a process where Group Decision Support Systems (GDSS) can be put to best use. In an academic environment the groups of teachers on the one hand and students on the other hand are directly addressed. Different study fields and departments in the organizational structure also need to be considered.

We have applied GDSS in the study programme reform process at two faculties: Faculty of Information Studies in Novo mesto, Slovenia (study programmes Informatics in Contemporary Society and Information Society) and School of
Advanced Social Studies, Slovenia (study programmes Intercultural Management and Sociology), using the GDSS tool Teamworks [5]. Additonal experiment was performed with the group of the students from the University of Maribor, Faculty of organizational sciences in order to compare gathered results. TeamWorks was developed to support group decision-making processes using the e-meeting paradigm. TeamWorks supports the execution of meetings by providing automated meeting minutes, agenda tools, idea gathering, categorisation and voting. It supports group collaboration, ensures anonymity of contributors and improves the efficiency of group decisionmaking process [6-11].

The purpose of the presented research covers three areas: a) to provide appropriate feedback from the students and staff regarding the reform of study programs, b) to analyse the dynamics of the creative process, c) to contribute to the further development of methodological and technical systems to support group decision making processes.

Four groups of students that were involved in the research came from the following faculties: a) Faculty of Information Studies in Novo mesto, b) School of Advanced Social Studies in Nova Gorica, c) Faculty of Organizational Sciences, University of Maribor. Staff members came from the following faculties: a) Faculty of Information Studies in Novo mesto, b) School of Advanced Social Studies in Nova Gorica. The diversity of the participating groups certainly contributes to the diversity of views on the reform of study programs.

\section{Methodology}

To support the decision making process we have used the GDSS TeamWorks [5] tool, which implements the e-meeting paradigm and acts as an intelligent agent. Russel and Norvig [12] noted since the $2^{\text {nd }}$ edition of their seminal book in 2003 [12] we have seen a widespread application of several Artificial Intelligence methods in addition to advances in the AI theory and algorithms. Perhaps we are nearing the era when the "intelligent" behaviour of appliances and application will be the norm, and the intelligence will be seen as an aspect of good design, and such solutions recognized as merely "userfriendly". Russel and Norvig [12] define AI as "define AI as the study of agents that receive percepts from the environment and perform actions." In this sense, the GDSS system used in the research presented in this paper embodies an intelligent 
agent, that implements simple decision methods for "Communicating, Perceiving and Acting" to take on several traditionally human roles present in a methodologically supported and structured meeting, i.e.:

- Meeting moderator: implements a meeting methodology to guide the participants through a series of meeting steps intended to bring them closer to a decision on the discussed problem.

- Meeting note-taker: documents the meeting steps and participant inputs in a structured document.

- Data analyst: applies quantitative methods to participant inputs to generate a statistical analysis of meeting events and results, giving insight to group dynamics in the meeting.

In this sense the GDSS is similar to the category of software popularly referred to as "wizards" (e.g. installation wizards, document creation wizards etc.), which implement AI methods usable for "simple decisions" as stated by Russel and Norvig [12], i.e. decision networks and multiattribute utility functions in order to automate a sequence of tasks.

Using the Teamworks GDSS, several activities were performed: collecting ideas (brainstorming), sorting ideas into categories, voting on priorities of categories and voting on the importance of ideas in each category. The TeamWorks GDSS system consists of a network of personal computers, where one of the computers acts as a TeamWorks server and others as clients.

The session participants are:

- decision group, in our case consisting of students and/or staff members,

- technical manager and

- content manager.

The technical manager of the session moderates the meeting using the TeamWorks server to ensure a smooth interaction of participants and progress according to the meeting agenda. The meeting should also include a content manager, familiar with the problem area and work methods, responsible for the session focus. Session management is simultaneously controlled and coordinated by the technical manager. All the participants should be able to monitor the session progress via the projection of the technical manager's workstation, displaying the initial question, as well as current ideas, the voting results and other activities. Implementation of the session and the installation of the system are presented in Fig. 1. After the initial problem presentation the brainstorming part of session is started. This part of session in our case lasted for 30 minutes. Basic principles to be followed during the session are: a) the quantity of ideas can increase quality, b) any idea is welcome, negative criticism and ideas are to be avoided, c) unusual ideas can initiate a positive change of problem perspective and c) a combination of existing ideas can generate new ideas.

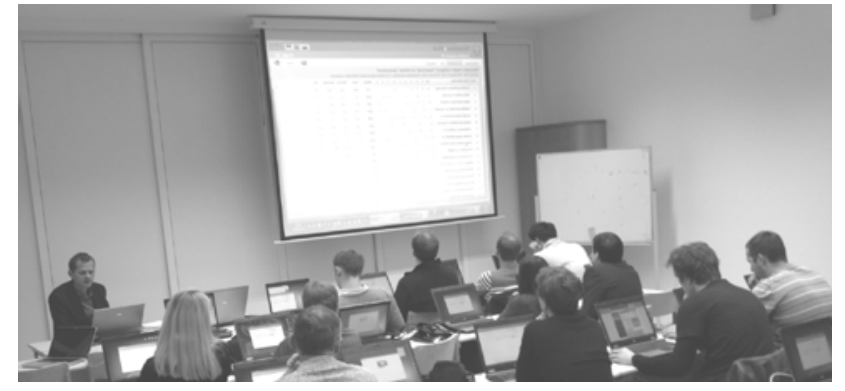

Fig. 1. Group session supported by TeamWorks [5] tool.

The mechanism of the collection of ideas is presented in Fig. 2. An adequate number of virtual sheets to record ideas on the topic/question about the reform of study program are generated for the participants. At the outset, one of the sheets is randomly sent to each participant. Participant writes/enters a new idea on the sheet. When an idea is entered, the sheet is forwarded to another randomly selected participant. Each participant can read the other participants' ideas on the sheet. Using this mechanism, ideas are circulating among the participants. The insight into the ideas of other participants contributes to better understanding of the topic/question and intensifies the creation of new ideas. New ideas generated by the group can be seen on the projection screen. The content manager usually comments newly formed ideas and seeks to promote the collection of innovative, strategic ideas. At the end of the session, the participants are invited to answer a questionnaire, which is used to obtain feedback on the session experience and suggestions for improvements.

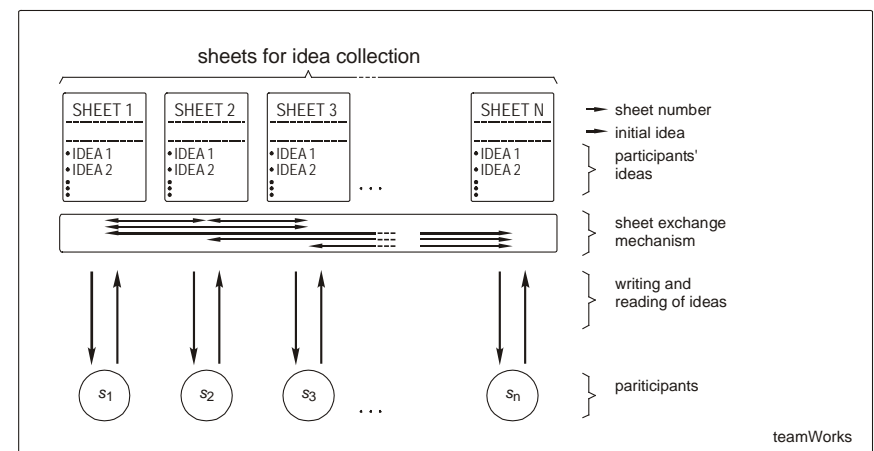

Fig. 2. Mechanism of sheet exchange between participants in Teamworks [5]

\section{RESULTS}

In the first iteration of present research, three groups were involved in the experiment. Their sizes were N1 $=15$ (11 male, 4 female), $\mathrm{N} 2=13$ ( 5 male, 8 female $)$ and N3 $=9$ ( 5 male, 4 female). Postgraduate students of the Faculty of Information Studies in Novo mesto (FIS I) participated in the first group, first year students of the Faculty of Information Studies in Novo mesto and students of the School of Advanced Social Studies in Nova Gorica (FIS II.) participated in the second group. The third group included students in the third year of undergraduate studies in the field of Information Systems, Faculty of Organizational Sciences University of Maribor. The problem/topic and a short introduction basic usage of the TeamWorks [5] tool were presented to each group of students. The initial question posed to participants was: "How can content and performance of the study be improved?" In all 
three groups brainstorming was conducted anonymously as each participant randomly picked a username and password from a set of leaflets with printed login information. The number of generated ideas and the intensity of the group are presented in Table 1. The number of ideas per participant generated in the course of $30 \mathrm{~min}$ is defined in the table as group intensity. Based on gathered data, the number of ideas in one minute is calculated and presented in the table.

TABLE I. THE NUMBER OF GENERATED IDEAS AND GROUP INTENSITY

\begin{tabular}{|l|r|r|r|}
\hline Group & FIS I. & FIS II. & FOV \\
\hline Number of ideas & 149 & 170 & 65 \\
\hline Number of participants & 15 & 13 & 9 \\
\hline Time [min] & 30 & 30 & 30 \\
\hline Num. ideas/par./min & 0.33 & 0.44 & 0.24 \\
\hline
\end{tabular}

One-way ANOVA was used to compare means of gathered ideas in groups. The results of ANOVA showed that the null hypothesis on equal number of gathered ideas regarding the group can not be rejected at 5\% significance level (Sig. $0,060>0.05)$. Therefore, there are no statistically significant differences between the average number of gathered ideas in discussed groups.

Fig. 3 shows the dynamics of idea gathering in three groups FIS I., FIS II., and FOV in the time period of 30 minutes $(1,800$ seconds). Time in seconds is shown on the $\mathrm{x}$ axis and number of ideas per participant per second is shown on the $y$ axis. The figure basically plots the frequency of idea generation per participant. For example, value of 1 on the $y$ axis means that one idea per second per participant was generated. In practice the values ranged from 0 to 0.014 ideas per participant per second, i.e. during the busiest period, a participant on average generated an idea approximately every 71 seconds. The diagram shows a significant increase in the frequency of idea gathering in the initial period with the frequency peaking at 313, 349 and 140 for FIS I., FIS II., and FOV seconds respectively. Differences in the intensity of group work are also shown in the diagram, where the efficiency of an individual in the group should be emphasized. It is interesting to notice that an average individual was more efficient at idea generation in the group of thirteen members (FIS II.) than in the larger group with fifteen members (FIS I.). An individual participant was the least efficient in the group FOV with nine members.

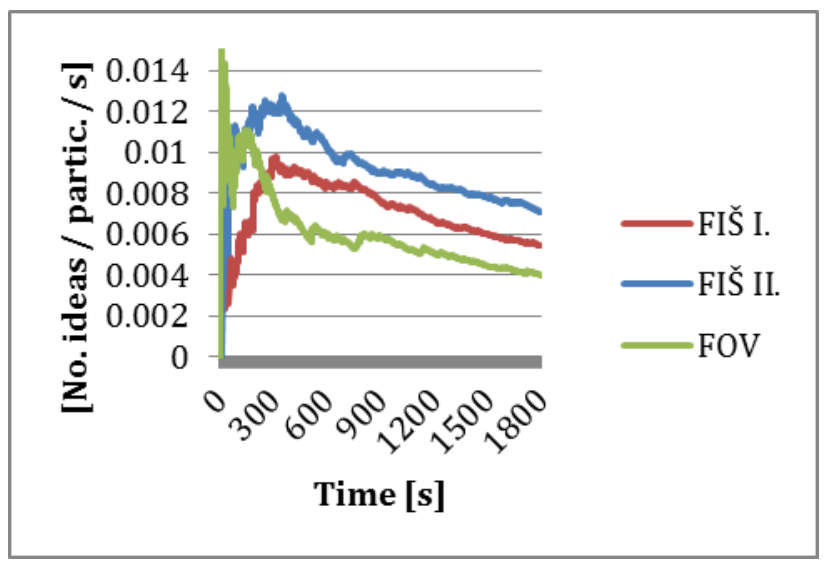

Fig. 3. The dynamics of idea gathering in three groups, FIS I., FIS II., and FOV.

Fig. 4 shows the same data as Fig.3, i.e. the dynamics of idea gathering in three groups FIS I., FIS II., and FOV in the time period of 30 minutes, however in this figure the time is divided into 5 minute slots to better identify the differences in the idea generation dynamics of the three groups. One could compare the differences between the intensity of the work of particular groups, where in the particular time interval the rank of the groups regarding the intensity of the work remains consistent.

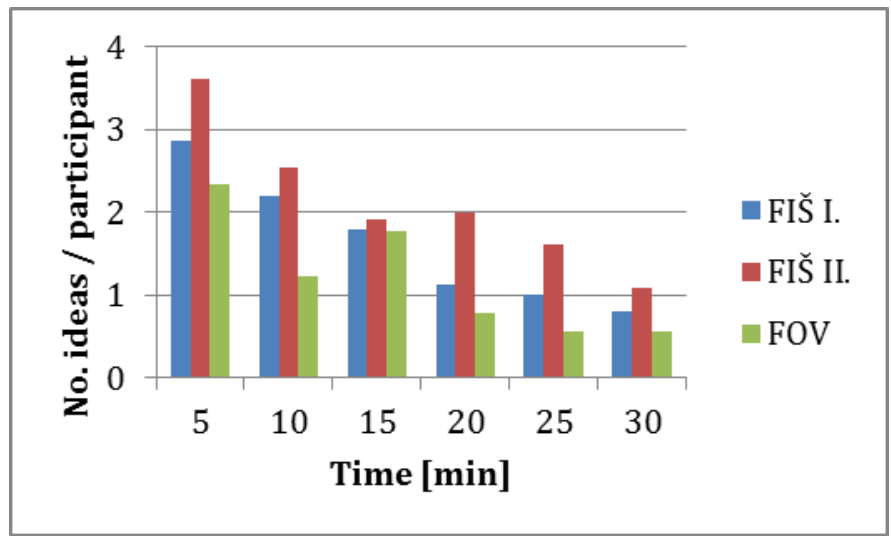

Fig. 4. The dynamics of idea gathering in three groups, FIS I., FIS II., and FOV averaged for 5 minute periods.

The differences in the process of idea generation can be seen in the analysis of the time between generated ideas. Fig. 5 and 6 show the distribution of time between generated ideas for group FIS I. and FIS II. A typical form of an exponential distribution is evident, but we cannot assume it is the Poisson process, since the input or acceptance capacity of ideas is unlimited. 


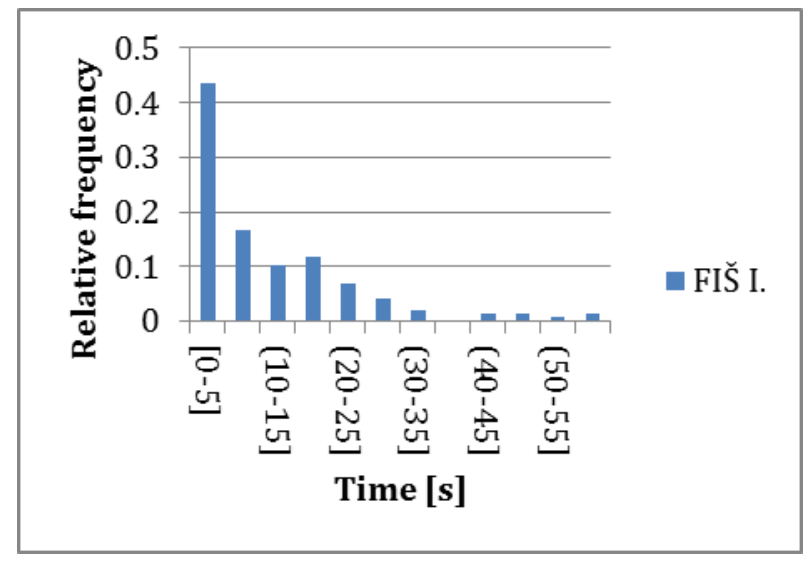

Fig. 5. The distribution of time between generated ideas, group FIS I.

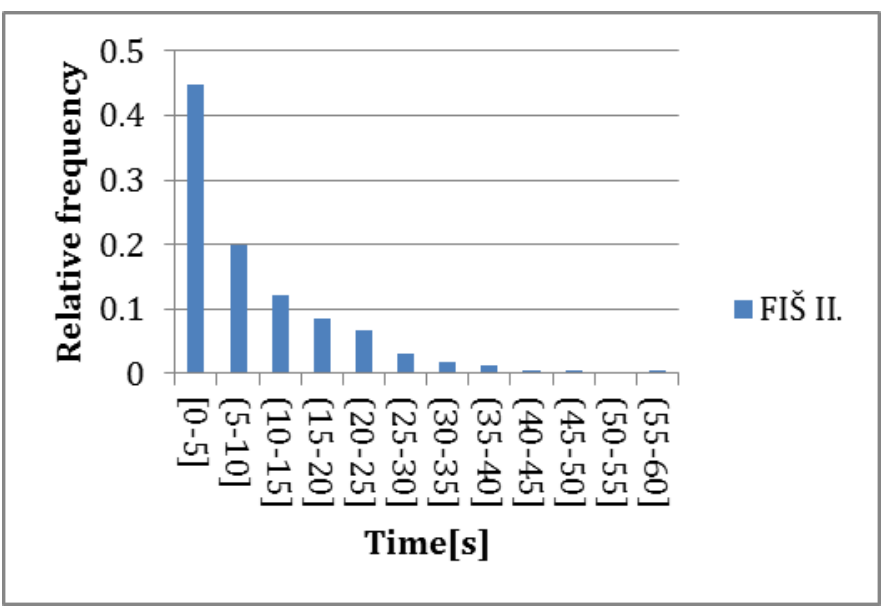

Fig. 6. The distribution of time between generated ideas, group FIS II.

The distribution of time between generated ideas for group FOV is presented in Fig. 7. A difference in the form of distribution can be seen, which indicates the differences of the groups. The presented distribution has all the characteristics of the uniform distribution.

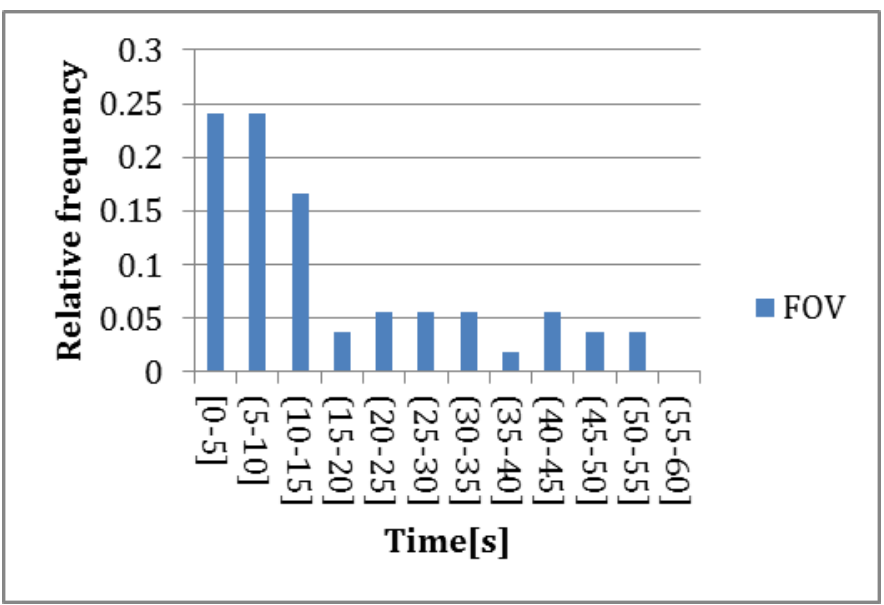

Fig. 7. The distribution of time between generated ideas, group FOV.

Considering the results of the groups the statistical test of differences in the work intensity in the group was performed.
The nonparametric Kruskal-Wallis test was used. A comparison of the work intensity in the three groups was carried out. The number of gathered ideas per participant in the time interval of five minutes was considered. Table 2 shows the data for the Kruskal-Wallis test.

TABLE II. DATA FOR THE KRUSKAL-WALLIS TEST.

\begin{tabular}{|r|l|r|r|}
\hline & Group & N & Average rank \\
\hline \multirow{3}{*}{ Intensity } & FIS I. & 6 & 11.25 \\
\cline { 2 - 4 } & FIS II. & 6 & 12.50 \\
\cline { 2 - 4 } & FOV & 6 & 4.75 \\
\cline { 2 - 4 } & Total & 18 & \\
\hline
\end{tabular}

Hypothesis about the different dynamics of the three groups can be confirmed at risk level $\mathrm{p}=0.05 ; \mathrm{X}^{2}=7.312, \mathrm{df}=2, \mathrm{p}=$ 0.026 . Here the Kruskal-Wallis Test was applied in order to compare the dynamics of the groups with 2 degrees of freedom for three groups.

The ideas that were rated as the most important for the improvement of content and execution of the study programmes are presented in Tables 3-5. These ideas are selected from the gained categories, up to four from particular category.

TABLE III. KEY PROPOSALS (FIS I. GROUP).

\begin{tabular}{|c|c|}
\hline Id. No. & Idea \\
\hline 1 & $\begin{array}{l}\text { Introduction of three different fields: 1) focus on } \\
\text { computer science; 2) focus on social sciences; 3) } \\
\text { focus on business - computer science }\end{array}$ \\
\hline 2 & $\begin{array}{l}\text { Increase the number of computer science courses } \\
\text { while reducing the number of social science courses }\end{array}$ \\
\hline$\overline{3}$ & Better faculty support in job search of students \\
\hline$\overline{4}$ & $\begin{array}{l}\text { More practical work and less theory, more group } \\
\text { work in classes }\end{array}$ \\
\hline 5 & Computer forensics as a mandatory class \\
\hline 6 & Block lectures \\
\hline 7 & $\begin{array}{l}\text { More interaction between students and professors } \\
\text { during lectures and less tedious lectures }\end{array}$ \\
\hline 8 & $\begin{array}{l}\text { The possibility of obtaining a professional certificate } \\
\text { via courses (e.g. Microsoft or Cisco) }\end{array}$ \\
\hline 9 & $\begin{array}{l}\text { More content on Moodle, supported by video } \\
\text { recordings of lectures and lab work }\end{array}$ \\
\hline 10 & No seminar papers and more computer lab work \\
\hline 11 & $\begin{array}{l}\text { Inclusion of "Living Labs" in the study process. } \\
\text { Students could then pass their ideas in the study } \\
\text { process }\end{array}$ \\
\hline 12 & $\begin{array}{l}\text { Open computer lab, as a sandbox for new ideas and } \\
\text { learning about computers and communication } \\
\text { equipment }\end{array}$ \\
\hline 13 & $\begin{array}{l}\text { Just one location for lectures and exercises / } \\
\text { relocation of universities and higher education } \\
\text { institutions into a science park or incubator }\end{array}$ \\
\hline$\overline{14}$ & $\begin{array}{l}\text { Simpler faculty's website / better information on the } \\
\text { remaining obligations of students / more transparent } \\
\text { student's web forms }\end{array}$ \\
\hline 15 & $\begin{array}{l}\text { Overly difficult schedule / schedule that is more } \\
\text { relaxed, fewer weekly lectures and exercises }\end{array}$ \\
\hline
\end{tabular}




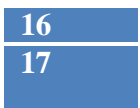

Discounts for buying a laptop via the faculty Access to e-learning materials, articles and other literature

TABLE IV. Key Proposals (FIS II. GRouP).

\begin{tabular}{|c|c|}
\hline Id. No. & Idea \\
\hline 1 & $\begin{array}{l}\text { Less busy schedule, less weekly workload, lecture } \\
\text { free days. }\end{array}$ \\
\hline 2 & More lab work and fewer lectures \\
\hline 3 & $\begin{array}{l}\text { One course at a time instead of several courses in } \\
\text { a week, fewer lectures }\end{array}$ \\
\hline 4 & Better organization of work \\
\hline 5 & $\begin{array}{l}\text { Provision of compulsory materials (in physical } \\
\text { form) for each class }\end{array}$ \\
\hline 6 & Material published prior to lectures on "Moodle" \\
\hline 7 & $\begin{array}{l}\text { Seminar paper does not present best current } \\
\text { practice (is outdated). Seminar papers are } \\
\text { expected to be mostly practice oriented without } \\
\text { theory. }\end{array}$ \\
\hline$\overline{8}$ & $\begin{array}{l}\text { Less extensive material, more in-depth treatment } \\
\text { of courses }\end{array}$ \\
\hline 9 & Too much theory, not enough cases \\
\hline 10 & $\begin{array}{l}\text { Start of lectures at 16:00 and no later (graduate } \\
\text { studies) }\end{array}$ \\
\hline 11 & $\begin{array}{l}\text { Timely information concerning the changes in } \\
\text { timetable }\end{array}$ \\
\hline 12 & $\begin{array}{l}\text { Career monitoring of the graduates and their } \\
\text { employability }\end{array}$ \\
\hline 13 & $\begin{array}{l}\text { Provide more practical experiences, which are } \\
\text { useful for further work }\end{array}$ \\
\hline 14 & $\begin{array}{l}\text { More practical examples and more integration of } \\
\text { current life situations in lectures }\end{array}$ \\
\hline 15 & $\begin{array}{l}\text { Increasing the number of parking spaces, better } \\
\text { location for lectures }\end{array}$ \\
\hline 16 & Occasional foreign guest lecturers (world-class) \\
\hline
\end{tabular}

TABLE V. Key Proposals (FOV Group).

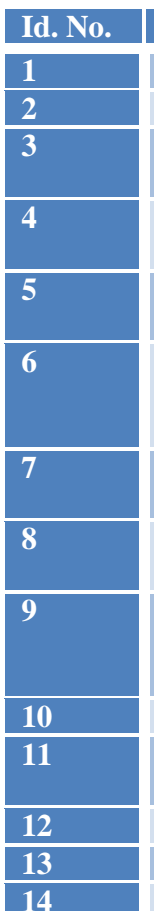
Idea

Modernization of the curriculum

Less theory and more practical examples

Fewer courses not related to the chosen field of study

More emphasis on IT classes and not learning the basics of e.g. Word and Excel

Provision of free courses for students (programming, foreign languages, ...)

Class Computing and informatics should keep pace with time and abandon the "assembler", etc... considered to be social networks, etc...

Fewer classes, which should be more profound and not superficial

Possibility to follow the lectures and tutorials online

E-classrooms contain boring documents and presentations without innovative approaches, audio and video contributions, interactivity ...

The possibility of implementing practices abroad Improve the efficiency of the student affairs office, more friendly attitude towards students Organise visits to successful companies

Faculty's help with job hunt

Better connection of the studies with bigger and

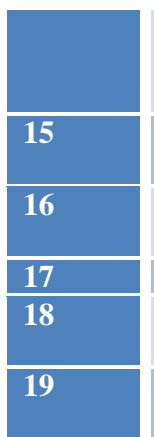

successful companies in Slovenia, given that the focus of the courses is IT for medium and large enterprises

Reducing the costs of part-time study, cofinancing

Encourage businesses to employ students full-time and co-finance part-time study

Free literature (books)

More literature in the library (books used in lectures)

Books in electronic form, which could have been purchased in the iStore, etc...

Fig. 8 shows the structure of the session implementation with TeamWorks tool [5]. The complexity of the described decision-making process can be anticipated since only a part of the structure is presented in the picture. FreeMind [13] opensource software is used to present the process.

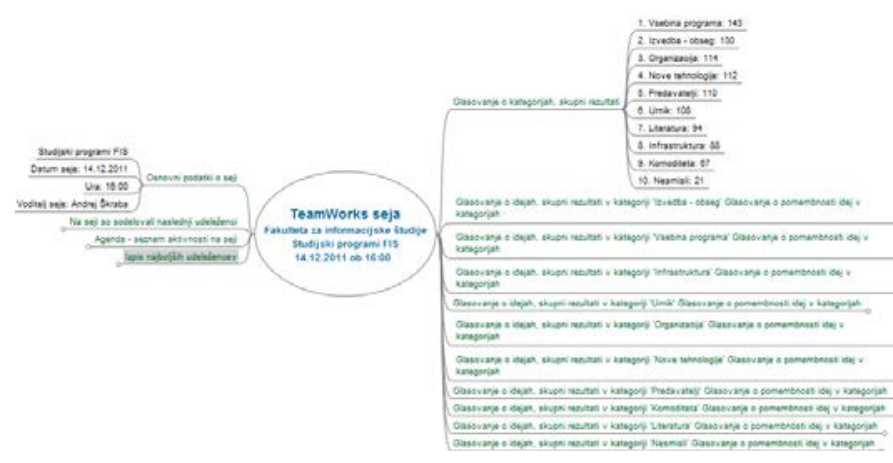

Fig. 8. Example of session structure export from TeamWorks [5] to FreeMind [13]. The representation of the structure is in the original language.

After the sessions, the participants answered a questionnaire that was used to obtain feedback and suggestions on the further development of the TeamWorks tool. The participants generally believe that the tool is effective for group decision-making and creative processes, but there is a lack of awareness that such tools and methodology actually exists.

\section{ADDITIONAL APPLICATION ON THE CASE OF DOCTORAL STUDY}

As the additional research, we have performed the case study of reforming doctoral study at the School of Advanced Social Studies in Nova Gorica (we will name the group as FUDS). Here 10 participants collaborated. The group was a mixture of students and staff members (professors). In the Fig. 9 the dynamics of the idea generation for the FUDS group is shown. If one compares the dynamics to the previous three groups one could observe, that these group did not show fast rise and the decline in the process of idea generation. Here rather stable generation of the ideas was observed. This could be due to the fact, that the topic was addressed more seriously since the professors collaborated in the session and also provide the feedback on the generated ideas. 


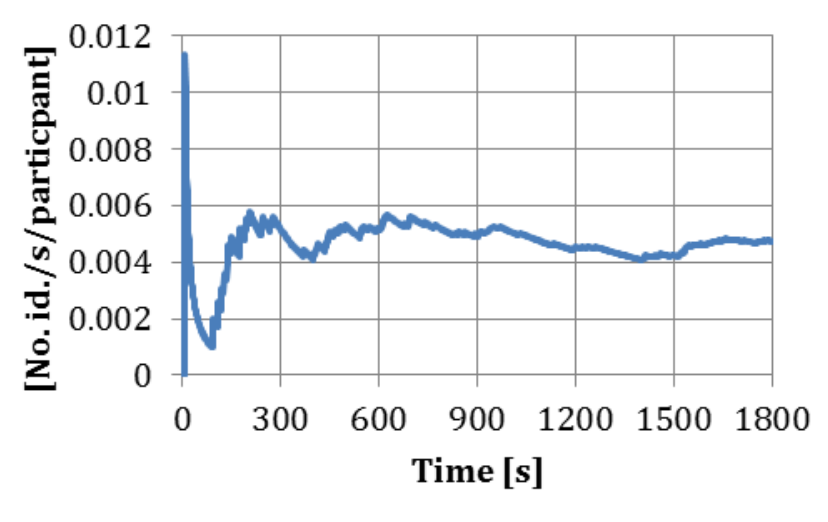

Fig. 9. Dynamics of the idea generation for the FUDS group.

Table VI shows the key proposals for the case of reforming doctoral studies from the FUDS group. The ideas were selected from different gathered categories.

TABLE VI. KEY PROPOSALS (FUDS. GROUP).

\begin{tabular}{|c|c|}
\hline Id. No. & Idea \\
\hline 1 & $\begin{array}{l}\text { According to possibilities, to involve } \\
\text { doctoral students in research projects carried } \\
\text { out at FUDS. }\end{array}$ \\
\hline$\overline{2}$ & $\begin{array}{l}\text { More meetings where doctoral students could } \\
\text { present their current research work }\end{array}$ \\
\hline 3 & Make special courses for particular topics \\
\hline$\overline{4}$ & $\begin{array}{l}\text { Intensify cooperation on the relation } \\
\text { student->professor and professor->student }\end{array}$ \\
\hline 5 & $\begin{array}{l}\text { To make "brainstorm" meetings among students, } \\
\text { who discuss their topics and how to improve them }\end{array}$ \\
\hline 6 & $\begin{array}{l}\text { Concrete and more frequent discussion on the } \\
\text { current state of the research work in the frame of } \\
\text { doctoral study. This should provide a possibility to } \\
\text { exchange ideas. }\end{array}$ \\
\hline 7 & $\begin{array}{l}\text { Free enrolment to NUK and other relevant } \\
\text { databases. }\end{array}$ \\
\hline 8 & $\begin{array}{l}\text { Paid doctoral researches from the side of } \\
\text { enterprises. }\end{array}$ \\
\hline 9 & $\begin{array}{l}\text { Cooperation with other faculties; subventions } \\
\text { for the student exchange. }\end{array}$ \\
\hline 10 & Lecture on the topic: how to write scientific paper. \\
\hline 11 & $\begin{array}{l}\text { Better connection regarding the research work in } \\
\text { the case of first year of study (help at the } \\
\text { involvement of the institution) }\end{array}$ \\
\hline 12 & $\begin{array}{l}\text { To provide an opportunity to involve students in } \\
\text { the research projects. }\end{array}$ \\
\hline 13 & Access to the newest scientific papers. \\
\hline 14 & Remote access to as many as possible databases. \\
\hline 15 & $\begin{array}{l}\text { Doctoral students should be motivated to attend } \\
\text { conferences. }\end{array}$ \\
\hline
\end{tabular}

The additional case study provides indication, that different group structure influences the intensity of work.

\section{DISCUSSION}

The results obtained by experiment groups represent important information for reforming the curricula of the study programmes. Because of the diversity of groups, with the participants from the three faculties, undergraduate as well as postgraduate studies, the results obtained are more diverse. Important indication is difference between the intensity of fourth, FUDS group work and other groups. This provides the starting point for the new research where the correlation between the group members profile and the efficiency of the group would be examined.

Diversity in this case is advantageous because it gives more extensive treatment of the problem and provides a wider range of ideas for improvement and reform of study programmes. In addition to the ideas gathered we have gained important information about the dynamics of the creative process, which is highly important for the development of contemporary information society. We believe that further in depth study of this type of process and usage of knowledge gained is necessary to develop better, more effective systems for group decision support. The feedback from the participants will serve to further develop and update the functionality of TeamWorks tool [5]. According to the opinion of decision group members this type of decision support tools should be regularly used in strategic decision making processes.

\section{REFERENCES}

[1] V. P. Bresfelean, N. Ghisoiu, R. Lacurezeanu and D.-A. Sitar-Taut, "Towards the Development of Decision Support in Academic Environments," in Proceedings of the 31st International Conference on Information Technology Interfaces, Cavtat, 2009.

[2] I. Zigurs, M. S. Poole in G. L. DeSanctis, "A Study of Influence in Computer-Mediated Group Decision Making," MIS Quaterly, Vol. 12, No. 4, pp. 625-644, 1988.

[3] W. W. Huang in K. K. Wei, "An empirical investigation of the effects of group support systems (GSS) and task type on group interactions from an influence perspective," Journal of Management Information Systems, Vol. 17, No. 2, pp. 181-206, 2000.

[4] M. S. Househ, A. Kushniruk, B. Carleton and D. Cloutier-Fisher, "A Literature Review on Distance Knowledge Exchange in Healthcare Groups: What Can We Learn From the ICT Literature?," Journal of Medical Systems, Vol. 35, No. 4, pp. 639-646, 2011.

[5] TeamWorks, "TeamWorks - Group Intelligence Concept," 2009. [Online]. Available: http://www.teamworks.si/prva_stran.php?id=home_e.php\&to=0\&la=1. [Accessed 286 2013].

[6] J. A. M. Vennix, Group model building: facilitating team learning using system dynamics, Chichester: Wiley, 1996.

[7] A. Škraba, M. Kljajić in R. Leskovar, "Group exploration of SD models - is there a place for a feedback loop in the decision process?," System Dynamics Review, Vol. 19, pp. 243-263, 2003.

[8] A. Škraba, M. Kljajić in M. Kljajić Borštnar, "The role of information feedback in the management group decision-making process applying system dynamics models," Group Decision and Negotiation, Vol. 16, No. 1, pp. 77-95, 2007.

[9] A. Škraba in B. Filipič, "IT supported regional development plan board meetings in the phase of gathering ideas $[Z$ informacijsko tehnologijo podprta izvedba sestankov regionalnih razvojnih odborov $\mathrm{v}$ fazi zbiranja idej],“ v R azvojni izzivi Slovenije, Ljubljana, Založba ZRC, 2009, pp. 241-250.

[10] A. Škraba, M. Kljajić, P. Papler, D. Kofjač in M. Obed, "Determination of recruitment and transition strategies, “' Kybernetes, Vol. 40, No. 9/10, pp. 1503-1522, 2011.

[11] A. Škraba in B. Rodič, "Usage and development group decision-support system in the case of information study program renewal [Uporaba in razvoj sistema za podporo skupinskemu odločanju pri prenovi študijskega programa informatike],“ v Dnevni slovenske informatike, Portorož, 2012.

[12] Russel,S., Norvig,P.: Artificial Intelligence: A Modern Approach (3rd Ed.), Prentice-Hall, Inc., Englewood Cliffs, New Jersey, 2010.

[13] FreeMind, "FreeMind," 30 June 2013. [Online]. Available: http://freemind.sourceforge.net/wiki/index.php/Main_Page.

\section{Creative Commons Attribution License 4.0 (Attribution 4.0 International, CC BY 4.0)}

This article is published under the terms of the Creative Commons Attribution License 4.0

https://creativecommons.org/licenses/by/4.0/deed.en_US 